\title{
Business Cycle Dynamics of a New Keynesian Overlapping Generations Model with Progressive Income Taxation*
}

\author{
By Burkhard Heer ${ }^{a, b}$ and Alfred Maußner ${ }^{c}$ \\ ${ }^{a}$ Free University of Bolzano-Bozen, School of Economics and Management, Via Sernesi \\ 1, 39100 Bolzano-Bozen, Italy, Burkhard.Heer@unibz.it \\ ${ }^{b}$ CESifo \\ ${ }^{c}$ University of Augsburg, Department of Economics, Universitätsstraße 16, 86159 Augs- \\ burg, Germany, alfred.maussner@wiwi.uni-augsburg.de
}

JEL classification: E31, E32, E52, D31, D58

Keywords: fluctuations, unanticipated inflation, wealth distribution, income distribution, progressive income taxation, Calvo price staggering

\begin{abstract}
In our dynamic optimizing sticky price model, agents are heterogeneous with regard to their age and their productivity. We find that the business cycle dynamics in the OLG model in response to both a technology shock and a monetary shock are similar, but not completely identical to those found in the corresponding representative-agent model. In particular, working hours in the OLG model decrease in response to a positive technological shock, since for young workers the income effect dominates the substitution effect. This is in line with the adverse effect of productivity shocks on employment found in structural vector autoregressions.
\end{abstract}

*We would like to thank Jonathan Heathcote, Victor Ríos-Rull, and Eric Young for their comments. All remaining errors are ours. Burkhard Heer kindly acknowledges support from the German Science Foundation (Deutsche Forschungsgemeinschaft DFG) during his stays at Georgetown University, University of Pennsylvania, and Stanford University. 


\section{Introduction}

Most business cycle research focuses on the behavior of the representative agent model and neglects the effects that are caused by the heterogeneity of agents. Notable exceptions are Ríos-Rull (1996) and Castañeda, Díaz-Giminénez, and Ríos-Rull (1998), among others. Ríos-Rull (1996) considers a stochastic OLG model for the study of the effects of a technology shock. He shows that the business cycle dynamics of the lifecycle model is basically the same as those of the infinitely-lived representative-agent model. Castañeda et al. (1998) explore the dynamics of the income distribution in a neoclassical growth model with heterogeneous infinitely-lived households. They demonstrate that five types of households are enough to replicate most of the findings on the US income distribution business cycle dynamics. Both studies consider a Walrasian economy. The present paper is most closely related to the one of Ríos-Rull (1996). Different from his model, agents are also heterogeneous within generations. For this reason, we are also able to replicate the observed income and wealth heterogeneity. In addition to both Ríos-Rull (1996) and Castañeda et al. (1998), we introduce money and sticky prices in our model so that we are able to also consider a monetary shock in addition to the productivity shock. Furthermore, we calibrate the model period equal to one quarter rather than one year. ${ }^{1}$ We consider a model period of one quarter to be more appropriate for the study of business cycle dynamics.

In essence, we confirm the results of Ríos-Rull (1996). The heterogeneous-agent OLG model behaves almost identical to the representative-agent model. We, however, find one noteworthy exception. Following a technology shock, aggregate hours decrease in the OLG model whereas they increase in the Ramsey model. In order to observe this effect in our model we need both the productivity-age profile and the heterogeneity within generations. A productivity shock then implies a heterogeneous response of the labor supply among workers depending on their productivity, their age, and their wealth. In this respect our paper provides another explanation for the negative response of working hours to a technology shock that Galí (1999) and Francis and Ramey (2002) identify in vector autoregressions. Francis and Ramey (2002) show that this finding

\footnotetext{
${ }^{1}$ In addition, we also apply a solution method that has not been used to the computation of such large-scale stochastic models before. While Ríos-Rull (1996) uses a solution method that is only applicable to a central-planning problem, Castañeda et al. (1998) use the algorithm suggested by Krussell and Smith (1998). Our study, therefore, is also of independent interest for the researcher of computational methods.
} 
is consistent with real business cycle models that incorporate habit persistence and investment adjustment costs. Our model points to the heterogeneity of workers. ${ }^{2}$

Our study also confirms the findings of Castañeda et al. (1998), even though our model emphasizes different channels of transmission for the productivity shock. In the Walrasian economy of the model by Castañeda et al. (1998), a productivity shock affects the factor prices and, hence, the income distribution. This effect is also present in our model. In addition, we model progressive income taxation and firms' profits. Therefore, a productivity shock also affects government taxes and transfers to the households. These effects, of course, overlap the standard factor price effects. We find that the distribution effect of a productivity shock in our model is similar to the one in Castañeda et al. (1998). In particular, the distribution of income becomes more equal after a positive productivity shock.

We further apply our model to study the fundamental question how monetary policy affects the distribution of income and wealth. Quite recently, this relationship has received renewed interest. Easterly and Fischer (2001) as well as Romer and Romer (1998) point out in their empirical analysis that inflation hurts the very poor. Galli and van der Hoeven (2001) provide a survey of the empirical literature. Moreover, there have been a few initial quantitative studies of the distributional effects of inflation that are based on general equilibrium models. These include studies by Erosa and Ventura (2002) and Heer and Süssmuth (2006) who focus on the effects of a change in the long-run inflation rate and, therefore, perform a comparative steady-state analysis of the endogenous wealth distributions. In both articles, a rise in the anticipated longrun inflation rate results in a rise of the wealth inequality. Erosa and Ventura (2002) emphasize the inflation's effect on the composition of the consumption good bundle. Higher inflation results in an increase of the consumption of the credit good at the expense of the consumption of the cash good, and richer agents have lower credit costs. Heer and Süssmuth (2006) model the observation that not all agents have access to the stock market and, therefore, poorer agents are less likely to hold assets whose real return is not reduced through higher inflation. All these studies, however, refrain from modelling the effects of unanticipated inflation.

In order to model the short-run effects of monetary policy, we assume that prices

\footnotetext{
${ }^{2}$ Christiano, Eichenbaum, and Vigfusson (2003) argue that the negative response of hours depends on the treatment of hours as a difference stationary process. Modelling hours as a stationary process they find that per capita hours increase in response to a technology shock.
} 
are sticky and adjust as in Calvo (1983). Following an unexpected rise of the money growth rate, we observe unexpected inflation. Prices and markups adjust endogenously

in our economy. As a consequence, both factor prices and the distribution of income change. In addition, as mentioned above, income is taxed progressively in our model. If there is unexpected inflation, the real tax burden of the income-rich agents increases, the so-called "bracket creep". We also consider the effect of inflation on pensions. In particular, unexpected inflation results in a reduction of real pensions as the government adjusts the pensions for higher-than-average inflation only with a lag. Consequently, following an expansionary monetary policy with an unexpected rise of inflation, the non-interest income distribution becomes more equal, while the effect on the total income distribution depends on the distribution of interest income (and, hence, the distribution of wealth).

The paper is organized as follows. In section 2, we describe the OLG model. The model is calibrated in section 3 , where we also present the algorithm for our computation in brief. The results are presented in section 4 . We compare the heterogeneous-agent with the corresponding representative-agent economy and make the interesting observation that the business cycle dynamics in these two models are not completely identical. We also present the effect of both a productivity and a monetary shock on the distribution of income and wealth. Section 5 concludes. The Appendix describes the stochastic OLG and Ramsey model and the solution method in more detail.

\section{The Model}

The model is based on the stochastic Overlapping Generations (OLG) model with elastic labor supply and aggregate productivity risk, augmented by a government sector and the monetary authority. The model is an extension of Ríos-Rull (1996).

Four different sectors are depicted: households, firms, the government, and the monetary authority. Households maximize discounted life-time utility with regard to their intertemporal consumption, capital and money demand, and labor supply. Firms in the production sector are competitive, while firms in the retail sector are monopolistically competitive and set prices in a staggered way a la Calvo (1983). The intermediate good firms produce using labor input and capital. The government taxes income progressively and spends the revenues on government pensions and transfers. Both aggregate productivity and monetary policy are stochastic. 


\section{$2.1 \quad$ Households}

Households live $T+T^{R}=240$ periods (corresponding to 60 years). Each generation is of measure $1 /\left(T+T^{R}\right)$. The first $T=160$ (=40 years) periods, they are working, the last $T^{R}=80$ periods ( $=20$ years), they are retired and receive pensions. Agents are also heterogeneous with regard to their productivity level $e(s, j)$. The productivity $e(s, j)$ depends on the age $s$ and the idiosyncratic productivity type $j \in\{1, \ldots, n e\}$. Individual productivity is non-stochastic, and an individual will not change his productivity type $j$ over his life time. The mass of type- $j$ agents in each generations is constant and denoted by $\mu(j)$. The $s$-year old household with productivity type $j$ holds real money holdings $M_{t}^{s, j} / P_{t}$ and capital $k_{t}^{s, j}$ in period $t$. He maximizes expected life-time utility at age 1 in period $t$ with regard to consumption $c_{t}^{s, j}$, labor supply $n_{t}^{s, j}$, and next-period money balances $M_{t+1}^{s+1, j}$, and real capital $k_{t+1}^{s+1, j}$ :

$$
E_{t} \sum_{s=1}^{T+T^{R}} \beta^{s-1} u\left(c_{t+s-1}^{s, j}, \frac{M_{t+s-1}^{s, j}}{P_{t+s-1}}, 1-n_{t+s-1}^{s, j}\right),
$$

where $\beta$ is a discount factor and expectations are conditioned on the information set of the household at time $t$. Instantaneous utility $u\left(c_{t}, \frac{M_{t}}{P_{t}}, 1-n_{t}\right)$ is assumed to be:

$$
u\left(c, \frac{M}{P}, 1-n\right)= \begin{cases}\gamma \ln c+(1-\gamma) \ln \frac{M}{P}+\eta_{0} \frac{(1-n)^{1-\eta}}{1-\eta} & \text { if } \sigma=1 \\ \frac{\left(c^{\gamma}\left(\frac{M}{P}\right)^{1-\gamma}\right)^{1-\sigma}}{1-\sigma}+\eta_{0} \frac{(1-n)^{1-\eta}}{1-\eta} & \text { if } \sigma \neq 1,\end{cases}
$$

where $\sigma>0$ denotes the coefficient of relative risk aversion. ${ }^{3}$ The agent is born without capital $k_{t}^{1, j}=0, j \in\{1, \ldots, n e\}$, but receives an initial cash endowment from the government $M_{t}^{1 j}$ that is fixed in terms of the beginning of period price level $P_{t-1}$ and equal for the different productivity types, i.e., $M_{t}^{1 j} / P_{t-1}=: m^{1}>0$ for all $t$ and $j$.

The $s$-year old working agent with productivity type $j$ faces the following nominal budget constraint in period $t$ :

$$
\begin{aligned}
& P_{t}\left(k_{t+1}^{s+1, j}-(1-\delta) k_{t}^{s, j}\right)+\left(M_{t+1}^{s+1, j}-M_{t}^{s, j}\right)+P_{t} c_{t}^{s, j} \\
& =P_{t} r_{t} k_{t}^{s, j}+P_{t} w_{t} e(s, j) n_{t}^{s, j}+P_{t} t r_{t}+P_{t} \Omega_{t}-P_{t} \tau_{t}\left(\frac{P_{t} y_{t}^{s, j}}{P_{t-1} \pi}\right), \\
& s=1, \ldots, T, \quad j=1 \ldots, n e .
\end{aligned}
$$

\footnotetext{
${ }^{3}$ We follow Castañeda, Díaz-Giminénez, and Ríos-Rull (2004) in our choice of the functional form for the utility from leisure. In particular, this additive functional form implies a relatively low variability of working hours across individuals that is in good accordance with empirical evidence.
} 
The working agent receives income from effective labor $e(s, j) n_{t}^{s, j}$ and capital $k_{t}^{s, j}$ as well as government transfers $t r_{t}$ and profits $\Omega_{t}$ which are spent on consumption $c_{t}^{s, j}$ and next-period capital $k_{t+1}^{s+1, j}$ and money $M_{t+1}^{s+1, j}$. He pays taxes on his nominal income $P_{t} y_{t}^{s, j}$ :

$$
P_{t} y_{t}^{s, j}=P_{t} r_{t} k_{t}^{s, j}+P_{t} w_{t} e(s, j) n_{t}^{s, j}
$$

The government adjust the tax income schedule at the beginning of each period for the average rate of inflation in the economy which is equal to the non-stochastic steady state rate $\pi$. Therefore, nominal income is divided by the price level, $P_{t-1} \pi$, and the tax schedule $\tau\left(\right.$.) is a time-invariant function of (deflated) income with $\tau^{\prime}>0$. Notice that when we have unanticipated inflation, $\pi_{t}=\frac{P_{t}}{P_{t-1}}>\pi$, the real tax burden increases as the agent's real income moves into a higher tax bracket, the so-called "bracket creep" effect.

The nominal budget constraint of the retired worker is given by

$$
\begin{aligned}
& P_{t}\left(k_{t+1}^{s+1, j}-(1-\delta) k_{t}^{s, j}\right)+\left(M_{t+1}^{s+1, j}-M_{t}^{s, j}\right)+P_{t} c_{t}^{s, j} \\
& =P_{t} r_{t} k_{t}^{s, j}+\text { Pen }_{t}+P_{t} t r_{t}+P_{t} \Omega_{t}-P_{t} \tau_{t}\left(\frac{P_{t} y_{t}^{s, j}}{P_{t-1} \pi}\right) \\
& s=T+1, \ldots, T+T^{R}, \quad j=1, \ldots, n e,
\end{aligned}
$$

with the capital stock and money balances at the end of the life at age $s=T+T^{R}$ being equal to zero, $k_{t}^{T+T^{R}+1, j}=M_{t}^{T+T^{R}+1, j} \equiv 0$ for all productivity types $j \in\{1, \ldots, n e\}$, because the household does not leave bequests. Furthermore, since retirement at age $T+1$ is mandatory, $n_{t}^{T+1, j}=n_{t}^{T+2, j}=\ldots=n_{t}^{T+T^{R}, j} \equiv 0$. Pen $n_{t}$ are nominal pensions and are distributed lump-sum. They are not taxed. Again, the government adjusts pensions each period for expected inflation according to $P e n_{t}=$ pen $P_{t-1} \pi$, where pen is constant through time. If inflation is higher then expected, $\pi_{t}>\pi$, the real value of pensions declines.

The real budget constraint of the $s$-year old household with productivity type $j$ is given by

$$
k_{t+1}^{s+1, j}+m_{t+1}^{s+1, j}=\left\{\begin{array}{l}
\left(1+r_{t}-\delta\right) k_{t}^{s, j}+\frac{m_{t}^{s, j}}{\pi_{t}}+w_{t} e(s, j) n_{t}^{s, j}+t r_{t}+\Omega_{t}-\tau_{t}\left(\frac{y_{t}^{s, j} \pi_{t}}{\pi}\right)-c_{t}^{s, j} \\
s=1, \ldots, T, \\
\left(1+r_{t}-\delta\right) k_{t}^{s, j}+\frac{m_{t}^{s, j}}{\pi_{t}}+\frac{p e n \pi}{\pi_{t}}+t r_{t}+\Omega_{t}-\tau_{t}\left(\frac{y_{t}^{s, j} \pi_{t}}{\pi}\right)-c_{t}^{s, j} \\
s=T+1, \ldots, T+T^{R},
\end{array}\right.
$$


where we define $m_{t}^{s, j} \equiv \frac{M_{t}^{s, j}}{P_{t-1}}$.

The necessary conditions for the households with respect to consumption $c_{t}^{s, j}, s=$ $1, \ldots, T+T^{R}$, next-period capital $k_{t+1}^{s+1, j}$, and next-period money $m_{t+1}^{s+1, j}$ at age $s=$ $1, \ldots, T+T^{R}-1$ in period $t$ are as follows:

$$
\begin{aligned}
\lambda_{t}^{s, j} & =u_{c}\left(c_{t}^{s, j}, \frac{M_{t}^{s, j}}{P_{t}}, 1-n_{t}^{s, j}\right)=\gamma\left(c_{t}^{s, j}\right)^{\gamma(1-\sigma)-1}\left(\frac{m_{t}^{s, j}}{\pi_{t}}\right)^{(1-\gamma)(1-\sigma)}, \\
\lambda_{t}^{s, j} & =\beta E_{t}\left[\lambda_{t+1}^{s+1, j}\left(1-\delta+r_{t+1}\left(1-\tau^{\prime}\left(y_{t+1}^{s+1, j} \frac{\pi_{t+1}}{\pi}\right) \frac{\pi_{t+1}}{\pi}\right)\right)\right], \\
\lambda_{t}^{s, j} & =\beta E_{t}\left[\frac{\lambda_{t+1}^{s+1, j}}{\pi_{t+1}}+\frac{u_{M / P}\left(c_{t+1}^{s+1, j}, \frac{M_{t+1}^{s+1, j}}{P_{t+1}}, 1-n_{t+1}^{s+1, j}\right)}{\pi_{t+1}}\right] \\
& =\beta E_{t}\left[\frac{\lambda_{t+1}^{s+1, j}}{\pi_{t+1}}+\frac{(1-\gamma)\left(c_{t+1}^{s+1, j}\right)^{\gamma(1-\sigma)}\left(m_{t+1}^{s+1, j}\right)^{(1-\gamma)(1-\sigma)-1}}{\pi_{t+1}}\right] .
\end{aligned}
$$

The optimal labor supply of the productivity $j$-type workers at age $s=1, \ldots, T$ is given by:

$$
\lambda_{t}^{s, j} w_{t} e(s, j)\left[1-\tau^{\prime}\left(y_{t}^{s, j} \frac{\pi_{t}}{\pi}\right) \frac{\pi_{t}}{\pi}\right]=u_{n}\left(c_{t}, \frac{M_{t}^{s, j}}{P_{t}}, 1-n_{t}^{s, j}\right)=\eta_{0}\left(1-n_{t}^{s, j}\right)^{-\eta} .
$$

\subsection{Production}

The description of the production sector is similar to Bernanke, Gertler, and Gilchrist (1999). A continuum of perfectly competitive firms produce the final output using differentiated intermediate goods distributed on $[0,1]$. These goods are manufactured by monopolistically competitive firms. Firms in the intermediate goods' sector set prices according to Calvo (1983).

Final Goods Firms. The firms in the final goods sector produce the final good with a constant returns to scale technology using the intermediate goods $Y_{t}(j), j \in[0,1]$ as an input:

$$
Y_{t}=\left(\int_{0}^{1} Y_{t}(j)^{\frac{\epsilon-1}{\epsilon}} d j\right)^{\frac{\epsilon}{\epsilon-1}}
$$


Profit maximization implies the demand functions:

$$
Y_{t}(j)=\left(\frac{P_{t}(j)}{P_{t}}\right)^{-\epsilon} Y_{t},
$$

with the zero-profit condition

$$
P_{t}=\left(\int_{0}^{1} P_{t}(j)^{1-\epsilon} d j\right)^{\frac{1}{1-\epsilon}} .
$$

Intermediate Goods Firms. The intermediate good $j \in[0,1]$ is produced with capital $K_{t}(j)$ and effective labor $N_{t}(j)$ according to:

$$
Y_{t}(j)=z_{t} K_{t}(j)^{\alpha} N_{t}(j)^{1-\alpha} .
$$

All intermediate producers are subject to an aggregate technology shock $z_{t}$ being governed by the following $\mathrm{AR}(1)$ process:

$$
\ln z_{t}=\rho_{z} \ln z_{t-1}+\varepsilon_{z t}
$$

where $\varepsilon_{z t}$ is i.i.d., $\varepsilon_{z t} \sim N\left(0, \sigma_{z}^{2}\right)$.

The firms choose $K_{t}(j)$ and $N_{t}(j)$ in order to maximize profits. In a symmetric equilibrium profit maximization of the intermediate goods' producers implies:

$$
\begin{aligned}
r_{t} & =g_{t} \alpha z_{t} K_{t}^{\alpha-1} N_{t}^{1-\alpha}, \\
w_{t} & =g_{t}(1-\alpha) z_{t} K_{t}^{\alpha} N_{t}^{-\alpha},
\end{aligned}
$$

where $g_{t}$ denotes marginal costs.

Calvo price setting. Let $\phi$ denote the fraction of producers that keep their prices unchanged. Profit maximization of symmetric firms leads to a condition that can be expressed as a dynamic equation for the aggregate inflation rate:

$$
\hat{\pi}_{t}=-\kappa \hat{x}_{t}+\beta E_{t}\left\{\hat{\pi}_{t+1}\right\} .
$$

with $\kappa \equiv(1-\phi)(1-\beta \phi) / \phi>0$ and $\hat{\pi}_{t}$ is the percent deviation of the gross inflation rate from its non-stochastic steady state level $\pi{ }^{4}$

\footnotetext{
${ }^{4}$ A detailed derivation of this relation can be found in Herr and Maußner (2005), Section A.4.
} 


\subsection{Monetary authority}

The nominal stock of money held by generations $s=2$ through $s=T+T^{R}, M_{t}$, grows at the exogenous rate $\theta$ :

$$
\frac{M_{t+1}}{M_{t}}=\theta_{t} \text {. }
$$

The seignorage is transferred lump-sum to the government:

$$
\text { Seign }_{t}=M_{t+1}-M_{t}+\sum_{j=1}^{n e} \frac{\mu(j)}{T+T^{R}} M_{t}^{1 j} .
$$

The growth rate $\theta_{t}$ follows the process:

$$
\hat{\theta}_{t}=\rho_{\theta} \hat{\theta}_{t-1}+\varepsilon_{\theta t}
$$

where $\varepsilon_{\theta t}$ is assumed to be i.i.d., $\varepsilon_{\theta t} \sim N\left(0, \sigma_{\theta}^{2}\right)$.

\subsection{Government}

Nominal government expenditures consists of pensions $P e n_{t}$, and government lumpsum transfers $P_{t} T r_{t}$ to households. Government expenditures are financed by an income $\operatorname{tax} \operatorname{Tax}_{t}$ and seignorage:

$$
P_{t} \operatorname{Tr}_{t}+\text { Pen }_{t}=\text { Tax }_{t}+\text { Seign }_{t}
$$

The income tax structure is chosen to match the current income tax structure in the US most closely. Gouveira and Strauss (1994) have characterized the US effective income tax function in the year 1989 with the following function:

$$
\tau(y)=a_{0}\left(y-\left(y^{-a_{1}}+a_{2}\right)^{-\frac{1}{a_{1}}}\right)
$$

and estimate the parameters with $a_{0}=0.258, a_{1}=0.768$ and $a_{2}=0.031$. We use the same functional form for our benchmark tax schedule. The average nominal income in 1989 amounts to approximately $\$ 50,000 .^{5}$

\footnotetext{
${ }^{5}$ We follow Castañeda et al. (2004).
} 


\subsection{Equilibrium conditions}

1. Aggregate and individual behavior are consistent, i.e. the sum of the individual consumption, effective labor supply, wealth, and money is equal to the aggregate level of consumption, effective labor supply, wealth, and money, respectively:

$$
\begin{aligned}
C_{t} & =\sum_{j=1}^{n e} \sum_{s=1}^{T+T^{R}} c_{t}^{s, j} \frac{\mu(j)}{T+T^{R}}, \\
N_{t} & =\sum_{j=1}^{n e} \sum_{s=1}^{T} n_{t}^{s, j} e(s, j) \frac{\mu(j)}{T+T^{R}}, \\
K_{t} & =\sum_{j=1}^{n e} \sum_{s=1}^{T+T^{R}} k_{t}^{s, j} \frac{\mu(j)}{T+T^{R}}, \\
m_{t} & =\sum_{j=1}^{n e} \sum_{s=1}^{T+T^{R}} m_{t}^{s, j} \frac{\mu(j)}{T+T^{R}} .
\end{aligned}
$$

2. Households maximize life-time utility (1).

3. Firms maximize profits.

4. The goods market clears:

$$
z_{t} K_{t}^{\alpha} N_{t}^{1-\alpha}=C_{t}+K_{t+1}+(1-\delta) K_{t} .
$$

5. The government budget (21) balances.

6. Monetary growth (18) is stochastic and seignorage is transferred to the government.

7. Technology is subject to a shock (14).

The non-stochastic steady state and the log-linearization of the model at the nonstochastic steady state are described in more detail in the appendix. In addition, we will compare our OLG model with the corresponding representative-agent model which we briefly describe in the following. 


\subsection{The representative agent model}

In the representative-agent Ramsey model we are, of course, unable to model pensions and to differentiate between working hours and effective labor input. Everything else is unchanged.

The representative household maximizes his infinite life-time utility

$$
\sum \beta^{t} u\left(c_{t}, M_{t} / P_{t}, 1-n_{t}\right)
$$

subject to

$$
\begin{aligned}
k_{t+1}+\frac{M_{t+1}}{P_{t}} & =\left(1-\delta+r_{t}\left(1-\tau\left[\left(\pi_{t} / \pi\right)\left(w_{t} n_{t}+r_{t} k_{t}\right)\right]\right)\right) k_{t} \\
& +\frac{M_{t}}{P_{t}}+\left(1-\tau\left[\left(\pi_{t} / \pi\right)\left(w_{t} n_{t}+r_{t} k_{t}\right)\right]\right) w_{t} n_{t}+t r_{t}+\Omega_{t}-c_{t}
\end{aligned}
$$

His decision variables in period $t=0$ are $M_{1}, k_{1}, c_{0}$, and $n_{0}$.

In this model, there are two predetermined state variables, the stock of capital $k_{t}$ and beginning-of-period real money balances

$$
m_{t}:=M_{t} / P_{t-1} \Rightarrow \frac{M_{t}}{P_{t}}=\frac{m_{t}}{\pi_{t}}, \pi_{t}:=\frac{P_{t}}{P_{t-1}} .
$$

Using these definitions, we can write the first-order conditions as follows:

$$
\begin{aligned}
\lambda_{t} & =u_{c}\left(c_{t}, \frac{M_{t}}{P_{t}}, 1-n_{t}\right)=\gamma\left(c_{t}\right)^{\gamma(1-\sigma)-1}\left(m_{t} / \pi_{t}\right)^{(1-\gamma)(1-\sigma)}, \\
\lambda_{t} & =\beta E_{t} \lambda_{t+1}\left(1-\delta+r_{t+1}\left(1-\tau^{\prime}\left[\left(\pi_{t} / \pi\right)\left(w_{t} n_{t}+r_{t} k_{t}\right)\right]\left(\pi_{t} / \pi\right)\right)\right) \\
\lambda_{t} & =\beta E\left[\frac{\lambda_{t+1}}{\pi_{t+1}}+\frac{u_{M / P}\left(c_{t+1}, \frac{M_{t+1}}{P_{t+1}}, 1-n_{t+1}\right)}{\pi_{t+1}}\right] \\
& =\beta E\left[\frac{\lambda_{t+1}}{\pi_{t+1}}+\frac{(1-\gamma)\left(c_{t+1}\right)^{\gamma(1-\sigma)}\left(m_{t+1} / \pi_{t+1}\right)^{(1-\gamma)(1-\sigma)-1}}{\pi_{t+1}}\right] \\
u_{n}\left(c_{t}, \frac{M_{t}}{P_{t}}, 1-n_{t}\right) & =\eta_{0}\left(1-n_{t}\right)^{-\eta}=\lambda_{t} w_{t}\left(1-\tau^{\prime}\left[\left(\pi_{t} / \pi\right)\left(w_{t} n_{t}+r_{t} k_{t}\right)\right]\left(\pi_{t} / \pi\right)\right)
\end{aligned}
$$




\section{Calibration and computation}

The OLG model is calibrated with regard to the characteristics of the US postwar economy. We use standard values for the parameters of the model. Periods correspond to quarters. The first $T=160$ periods, agents are working, the remaining $T^{R}=80$ periods they are retired.

\subsection{Preferences}

$\beta$ is set equal to 0.9909 implying a non-stochastic steady state annual real rate of return equal to $r\left(1-\tau^{\prime}\right)-\delta=4.5 \%$ and an annualized capital-output ratio equal to $K / Y=2.1$. The relative risk aversion coefficient $\sigma$ is set equal to 2.0. $\eta_{0}=0.26$ is set so that the average labor supply is approximately equal to $1 / 3, \bar{n} \approx 1 / 3$. Furthermore, we choose $\eta=7.0$ which implies a conservative value of 0.3 for the Frisch labor supply elasticity. ${ }^{6} \gamma$ is chosen so that the (annualized) average velocity of money $P Y / M$ is equal to the velocity of M1 during 1960-2002, which is equal to approximately 6.0. This requires $\gamma=0.981$.

\subsection{Government}

Pensions are constant. We choose a non-stochastic replacement ratio of pensions relative to average net wage earnings $\zeta$ equal to $30 \%, \zeta=\frac{p e n_{t}}{(1-\bar{\tau}) w_{t} \bar{n}_{t}}$, where $\bar{n}_{t}$ and $\bar{\tau}$ are the average labor supply and the income tax rate of the average income in the non-stochastic steady state of the economy, respectively. The calibration of the tax schedule follows Goveira and Strauss (1994). We adjust the parameter $a_{2}$ in (22) so that the average (and also the marginal) tax rate on annual average US-income equals the quarterly tax rate on average income in the model.

\footnotetext{
${ }^{6}$ The estimates of the Frisch intertemporal labor supply elasticity $\eta_{n, w}$ implied by microeconometric studies and the implied values of $\gamma$ vary considerably. MaCurdy (1981) and Altonji (1986) both use PSID data in order to estimate values of 0.23 and 0.28, respectively, while Killingsworth (1983) finds an US labor supply elasticity equal to $\eta_{n, w}=0.4$. Domeij and Floden (2006), however, argue that these estimates are biased downward due to the omission of borrowing constraints.
} 


\subsection{Monetary authority}

In accordance with Cooley and Hansen (1995), the quarterly inflation factor is set equal to $\pi=1.013$. Money growth follows an AR(1)-process. For the postwar US economy, Cooley and Hansen estimate $\rho_{\theta}=0.49$ and $\sigma_{\theta}^{2}=0.0089$. The initial endowment with money equals 21 percent of the average disposable income of the first generation. This is about the amount of money held by the 21 year old US citizens according to the 1994 PSID survey. ${ }^{7}$

\subsection{Production}

The production elasticity of capital $\alpha=0.36$ and the quarterly depreciation rate $\delta=$ 0.019 are taken from Prescott (1986) and Cooley and Hansen (1995), respectively. The annual quarterly fraction of producers that do not adjust their prices in any quarter is set equal to $\phi=0.25$. This value is smaller than the value chosen, e.g., in Bernanke et al. (1999), who use $\phi=0.75$, yet it introduces sufficient nominal rigidity into our model. Following empirical evidence presented by Basu and Fernard (1997), we set the average mark-up at the amount of $1 / g=1.2$ implying a constant elasticity of substitution between any two intermediate goods equal to $\epsilon=6$. The parameters of the $\mathrm{AR}(1)$ for the technology are set equal to $\rho_{z}=0.95$ and $\sigma_{z}=0.007$ as in Cooley and Hansen (1995).

\subsection{Individual productivity}

The idiosyncratic productivity level is given by $e(s, j)=e^{\bar{y}^{s}+x^{j}}$, where $\bar{y}^{s}$ is the mean log-normal income of the $s$-year old and $x^{j}$ is the idiosyncratic component. The mean efficiency index $\bar{y}^{s}$ of the $s$-year old is taken from Hansen (1993) and is interpolated to in-between quarters. As a consequence, the model replicates the cross-section age distribution of earnings of the US economy. The age-productivity profile is hump-shaped and earnings peak at age 50 corresponding to the model period 121 (not displayed). With regard to the idiosyncratic component $x^{j}$, we follow Huggett (1996) and choose a lognormal distribution of earnings for the 20-year old with a variance equal to $\sigma_{y^{1}}^{2}=0.38$

\footnotetext{
${ }^{7}$ We use data from the 1994 PSID data and wealth file. We included only households with strictly positive cash holdings in our sample. Money is defined as money in checking or savings accounts, money market funds, certificates of deposit, government savings bonds, and treasury bills.
} 
and mean $\bar{y}^{1}$. The productivity state $x^{j}$ is equally spaced and ranges from $-\sigma_{y^{1}}$ to $\sigma_{y^{1}}$. We discretize the state space by using $n e=2$ values and normalize $e^{x^{j}}$ so that $\sum_{j=1}^{n e} \mu(j) e^{x^{j}}=1 .^{8}$ For $n e=2$, we have $\mu(j)=0.5$ for $j=1,2$.

\subsection{Calibration of the Ramsey model}

In this model we calibrate the tax function so that the marginal tax rate paid by the representative household in the non-stochastic steady state equals the marginal tax rate on the average US-income. The government's tax revenues are transferred lump-sum to the representative agent. Capital's share is $\alpha=0.36$ and $\delta$ equals 0.019 , as is the case in the OLG model. The parameters that determine the properties of the productivity shock and the money supply shock are the same as those used in the simulations of the OLG model. The remaining parameters are set as follows: $\beta, \gamma$ and $\eta_{0}$ are chosen so that

- the annualized capital-output ratio is the same in both models (i.e., $K / Y=2.1$ )

- the representative agent works $n=1 / 3$ hours,

- the velocity of M1 is the same in both models (i.e., $Y /(M / P)=1.5$ )

Table 1 summarizes our choice of parameters for both models.

Table 1

Parameterization of the OLG and the Ramsey model

\begin{tabular}{llllll}
\hline \hline Preferences & & & & & \\
- OLG & $\beta=0.9909$ & $\sigma=2$ & $\gamma=0.981$ & $\eta=7$ & $\eta_{0}=0.26$ \\
- Ramsey & $\beta=0.9889$ & $\sigma=2$ & $\gamma=0.981$ & $\eta=7$ & $\eta_{0}=0.106$ \\
Production & $\alpha=0.36$ & $\delta=0.019$ & $\rho_{Z}=0.95$ & $\sigma_{Z}=0.007$ & \\
Market Structure & $\epsilon=6.0$ & $\phi=0.25$ & & & \\
Money Supply & $\pi=1.013$ & $\rho_{\theta}=0.49$ & $\sigma_{\theta}=0.0089$ & & \\
Government & $\zeta=0.3$ & $a_{0}=0.258$ & $a_{1}=0.768$ & $a_{2}=0.031$ & \\
\hline
\end{tabular}

\footnotetext{
${ }^{8}$ The number of productivity states $n e=2$ is already found to generate sufficient heterogeneity in wealth and income.
} 


\subsection{Computation}

In order to compute business cycle dynamics of the model, we first need to compute the non-stochastic steady state of the model. Secondly, we log-linearize the model around the non-stochastic steady state.

The non-stochastic steady state is computed by solving the respective system of nonlinear equations consisting of the first-order conditions of the generation born at time $t$, the government's budget constraint, and the aggregate consistency conditions. This is a system of several hundred variables (strictly speaking $\left(2\left(T+T^{R}-1\right)+T\right) n e$ variables). We employ a non-linear equations solver that takes care of the admissible bounds within which the solution must lie. To obtain reasonable initial values, we started with a simplified version of our model, where it is easy to solve for the optimal time profile of the capital stock. We expanded this model in several steps to the model given above.

Thereafter, we log-linearize the model around the non-stochastic steady. This linear rational expectations model can be solved by, e.g., applying the method of Blanchard and Kahn (1980), (see King, Plosser, and Rebelo, 1988) or of King and Watson (2002). ${ }^{9}$

\section{Results}

In this section, we compare the heterogeneous-agent OLG model to the representativeagent case and will find out that the two economies display similar, but not identical behavior, a result that is in good accordance with those in the non-monetary models of Krussell and Smith (1998) and Ríos-Rull (1996).

\footnotetext{
${ }^{9}$ The method that underlies our computation of the policy functions of the log-linearized model is explained in more detail in Chapter 2.3 in Heer and Maußner (2005) and applied to large scale dynamic systems of several hundred state variables and controls in Chapter 7.2.2. Both the Gauss code of the non-linear equations solver and the computation of the policy functions can be downloaded from the web side that accompanies Heer and Maußner (2005). The URL is www.wiwi-uni.augsburg.de/vwl/maussner/dgebook/download.html. The programs that solve and simulate the OLG and the Ramsey are in www.wiwiuni . augsburg.de/vwl/maussner/englisch/chair/maussner/pap/demp.zip.
} 


\subsection{The non-stochastic steady state}

Our OLG model displays the behavior that is typical for this kind of model. The wealth-age profile is hump-shaped as displayed in the upper left graph in Figure 1. Notice that due to the hump-shaped age-productivity profile (not displayed) households dissave during the first 61 quarters (=15 years). Only at real lifetime age 35 do they start to build up positive savings. Agents with higher productivity attain higher levels of capital, money balances, and consumption. In addition, consumption as displayed in the lower right graph in Figure 1 is increasing over the life-time as the discount rate is smaller than the interest rate. ${ }^{10}$ Notice that the household behavior changes abruptly as they enter retirement. This kind of behavior is absent from most standard OLG models. Consumption growth increases at retirement, while there is a downward jump in the real money stock. The reason is the presence of progressive income taxation in our model. In the first period of retirement at age 60.25, taxable income falls and the tax rate on capital income is much smaller than during working life. For this reason, the after-tax rate of return on real capital income increases. As a consequence, consumption growth is higher, and the household readjusts its portfolio allocation. The premium on the return on capital relative to the one on money has increased, and the real money stock is reduced as can be seen from the upper right picture in Figure 1. Furthermore, labor supply (lower left graph) attains a maximum at around age 30 because the age-specific productivity is rather low at young ages. Labor supply also attains its maximum prior to the maximum in the hourly wages because older agents have higher wealth and work fewer hours. Notice that high-productive agents work less hours than agents with low productivity because the income tax is progressive. ${ }^{11}$

In our economy, income and wealth are distributed unequally. The heterogeneity of income is in good accordance with the one observed empirically. In particular, the Gini coefficient of total gross income amounts to 0.34 and the Gini coefficient of disposable income equals 0.31. For the US economy, Henle and Ryscavage (1980) estimate an average US earnings Gini coefficient for men of 0.42 in the period 1958-77, while Castañeda et al. (1998) report a Gini coefficient equal to $0.351 .{ }^{12}$ The distribution of

\footnotetext{
${ }^{10}$ In order to imply a more realistic consumption-age profile, we may have introduced stochastic survival probabilities; in this case, consumption declines at old age. However, our quantitative results are not sensitive to this modelling choice and, therefore, we kept the model as simple as possible.

${ }^{11}$ If we assumed a flat tax rate on income instead, high-productive workers would work more than their low-productive contemporaries.

${ }^{12}$ The latter estimate is a little lower and in better accordance with our results because the authors
} 
Figure 1

Non-stochastic Steady State


wealth in our model is also close to the one observed empirically. In our model, the Gini coefficient of wealth amounts to 0.64, whereas Greenwood (1983), Wolff (1987), Kessler and Wolff (1992), and Díaz-Giménez, Quadrini, and Ríos-Rull (1997) estimate Gini coefficients of the wealth distribution for the US economy in the range of 0.72 (single, without dependents, female household head) to 0.81 (nonworking household head). ${ }^{13}$ Our model only fails to model the wealth concentration among the very rich agents. In order to replicate the wealth distribution of the top quintile, one had to introduce entrepreneurship as in Quadrini (2000).

calculate the Gini coefficient using only six observations to approximate the Lorenz curve.

${ }^{13}$ Huggett (1996) shows that we are able to replicate the empircally observable heterogeneity of wealth in a computable general equilibrium model if we introduce both life-cycle savings and individual earnings heterogeneity. 


\subsection{Productivity shock}

In Figure 2, the impulse response functions of aggregate variables to a technology shock $\varepsilon_{z, 2}=1$ in period 2 (and zero thereafter) are presented. In the first row, the percentage deviations of the variables technology level $z_{t}$, output $Y_{t}$, consumption $C_{t}$, and investment $I_{t}$ are graphed, in the second row, we illustrate the percentage deviations of effective labor input $N_{t}$ and working hours (the dotted line), capital $K_{t}$, real money $m_{t}$, and the inflation factor $\pi_{t}$, while in the third row, you find the behavior of marginal costs $g_{t}$ (the inverse of the mark-up), profits $\Omega_{t}$, the real interest $r_{t}$, and the wage rate $w_{t}$.

Figure 2

Technology Shock in the OLG Model
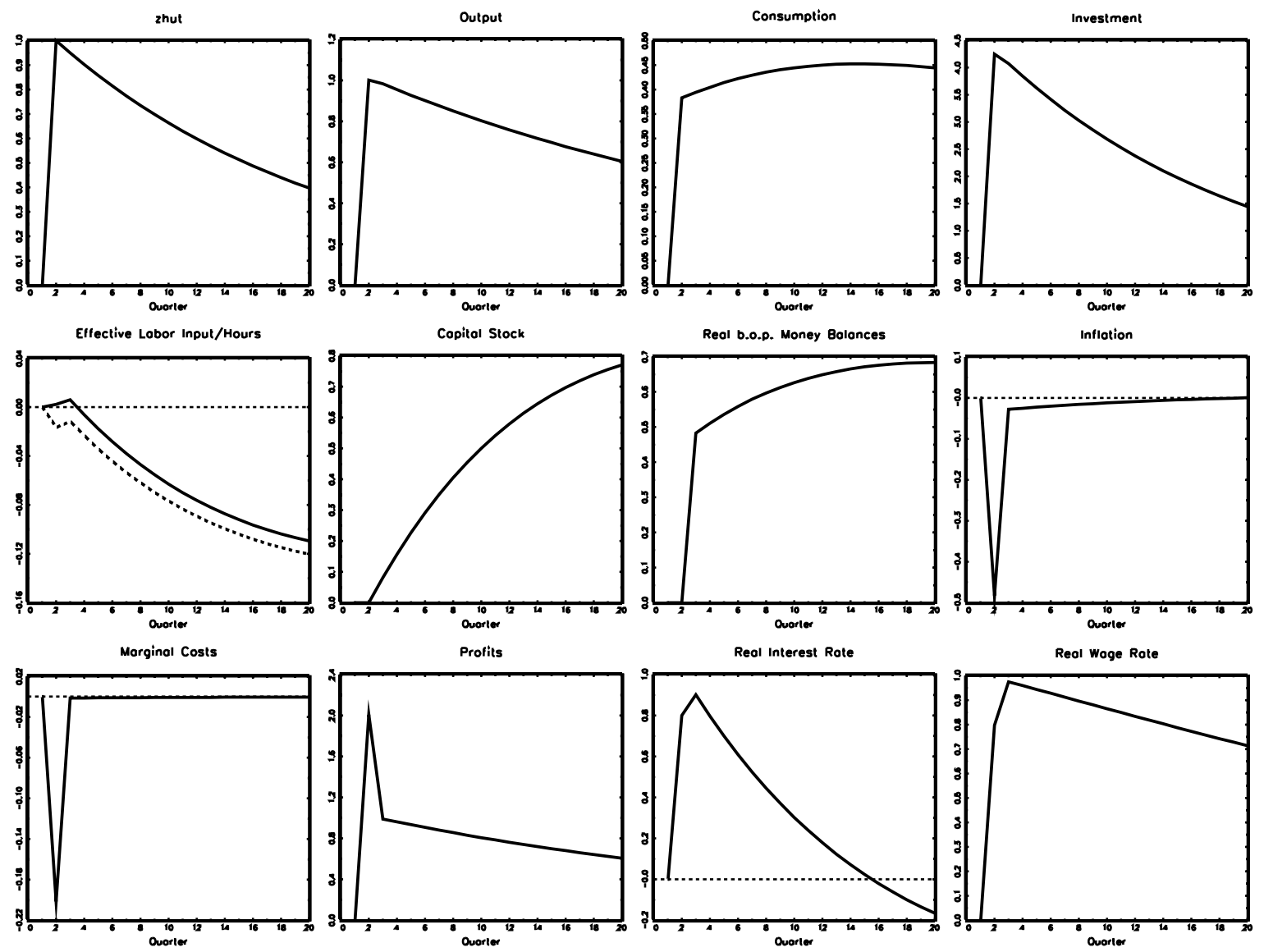

Following an unexpected increase of the technology level by 1\%, output increases by $1.0 \%$ as well. On impact, effective labor input increases slightly whereas working hours decrease. Subsequently both effective labor input and hours decrease. This result stems 
Figure 3

Technology Shock in the OLG Model and Distribution

Gini capital

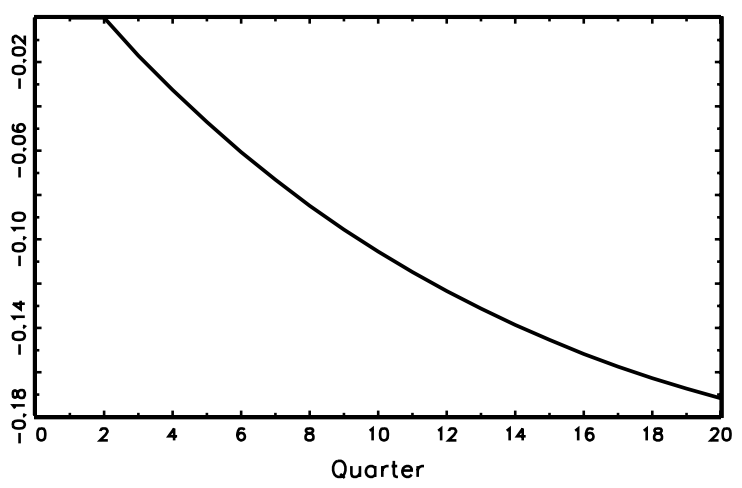

Gini wealth

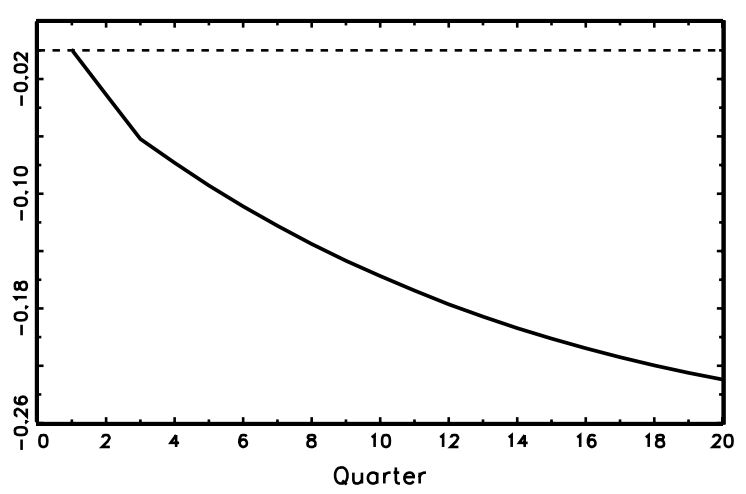

Gini money

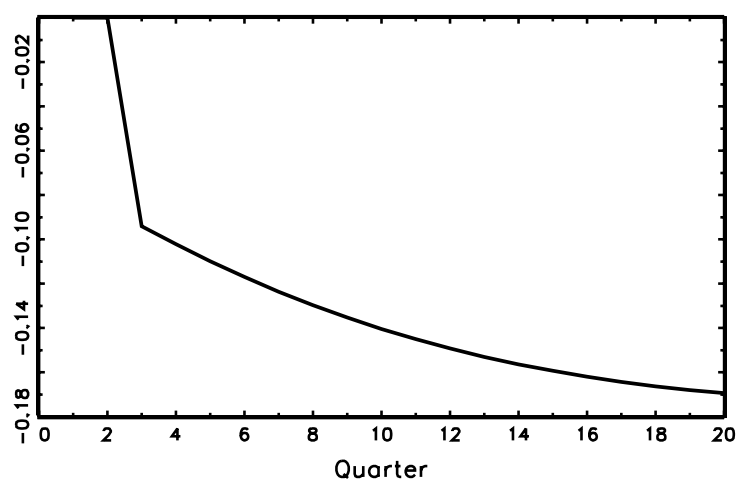

Gini market/disposable income

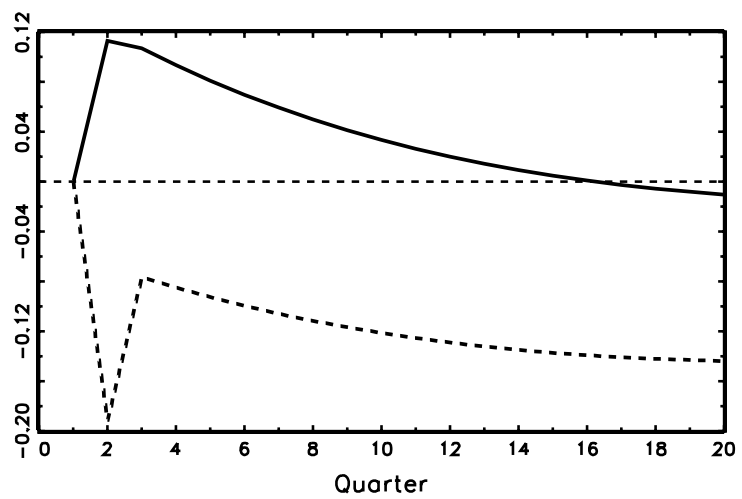

from the reactions of the younger and poorer agents: the income effect associated with the increase of profits and transfers dominates the substitution effect of higher real wages and they demand more leisure. ${ }^{14}$ Since older agents are more productive and, thus, earn higher wages, and since for them the discounted value of the increased profit stream is smaller, their supply of working hours increases, which also explains why effective labor input increases whereas working hours decrease at impact. Given the recent discussion on the empirical relation between productivity shocks and working hours (see Christiano et al., 2003 and the literature cited therein) we cannot say that this reaction is at odds with the current empirical wisdom. Quite on the contrary, our model provides a possible clue to the negative relation between productivity shocks

\footnotetext{
${ }^{14}$ The reduction in profits in period $t=3$ also explains the spike in period $t=3$ in the impulse responses of effective labor and working hours.
} 
and working hours. Inflation declines and most of the price adjustment takes place in the first period of the shock (period 2). As the productivity increases, both factor prices (wages and interest rate) increase. In addition, profits increase markedly in the first period.

The behavior of the wealth and income distribution in response to a technology shock is displayed in Figure 3. Both, the distribution of wealth and the distribution of disposable income become more equal although the effects are small: a one percent shock decreases the Gini coefficient of wealth (disposable income) by about 0.23 percent (0.20 percent). In order to understand these effects consider, first, the distribution of market income, i.e., the sum of wages and rental income from capital (solid line in the lower right graph of Figure 3). As explained above, the increase of profit income reduces the labor supply of young and poor households, whereas older and rich households for whom profit income is a much smaller share of their total income - supply more hours. In addition, the older and richer households benefit from the higher rental rate of capital relatively more than younger and poorer generations. Therefore, the distribution of market income becomes more unequal. There are several effects that explain the more equal distribution of disposable income, i.e., market income plus profits and transfers minus taxes. Profits and transfers are distributed lump-sum. Profits increase sharply in the first period of the shock and they remain above the normal level for several periods. ${ }^{15}$ Moreover, the real value of pensions also surges in the first period of the shock. The increased market income raises taxes and the government's transfer payments rise. In addition, richer and older agents pay relatively higher taxes. The more equal distribution of wealth is a direct consequence of the more equal distribution of disposable income, reinforced by the fact that poorer agents increase their capital stock relatively more than richer ones.

We find that the behavior of our heterogeneous-agent economy in response to a technology shock is similar to the one in the corresponding representative-agent economy. In Figure 4, we compare the impulse responses of the aggregate variables for the representative agent model (dotted line) with those of the heterogeneous-agent OLG model (solid line). The ordering of the variables is exactly as in Figure 2. Qualitatively, the responses are the same for all variables, except for working hours. The representative agent supplies additional hours of work in the first five quarters following the shock.

\footnotetext{
${ }^{15}$ The spike in profits in the first period of the shock also explains the spike in the Gini of disposable income (dotted line in the lower right graph of Figure 3).
} 
Figure 4

Productivity Shock in the Representative Agent Economy
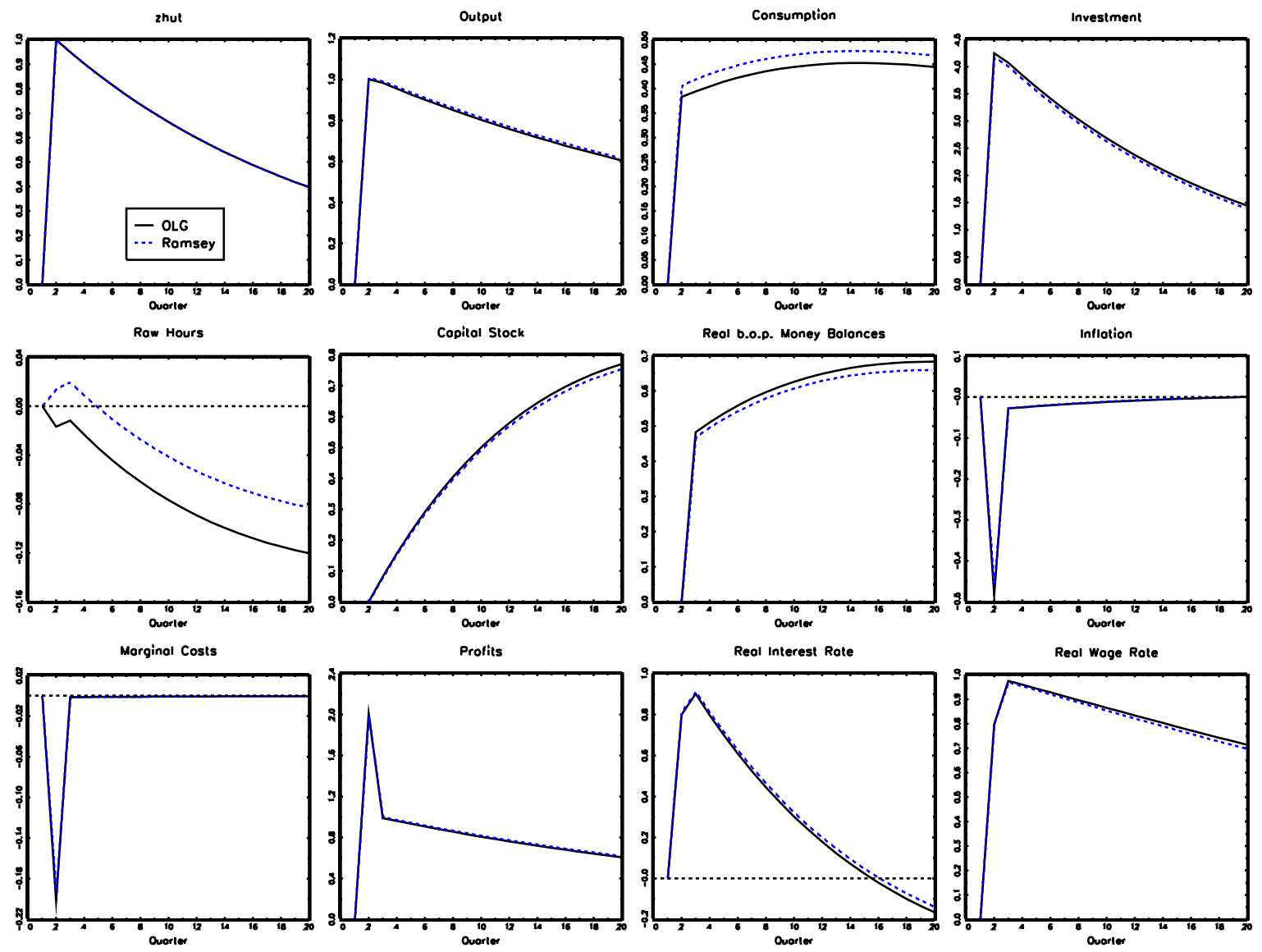

Even though the impulse responses for working hours differ between the two models, the reaction of output is the same. One has to keep in mind that effective labor and raw hours react differently to a productivity shock in the OLG model since the more productive workers increase their labor supply relative to the less productive workers. Since empirical research on the impulse response of working hours after a technology shock has focused on raw hours, our OLG model provides a possible resolution of this puzzle.

\subsection{Monetary shock}

An expansionary monetary shock increases demand. As prices are sticky and firms are monopolistic competitors in the intermediate goods sector, output and employment increases. The impulse response functions of aggregate variables to a monetary growth shock $\varepsilon_{\theta, 2}=1$ in period 2 (and zero thereafter) are presented in Figure 5. Again, the 
ordering is as in Figure 2 except for the upper left graph where the response of the money growth rate is displayed rather than the response of the technology shock.

Figure 5

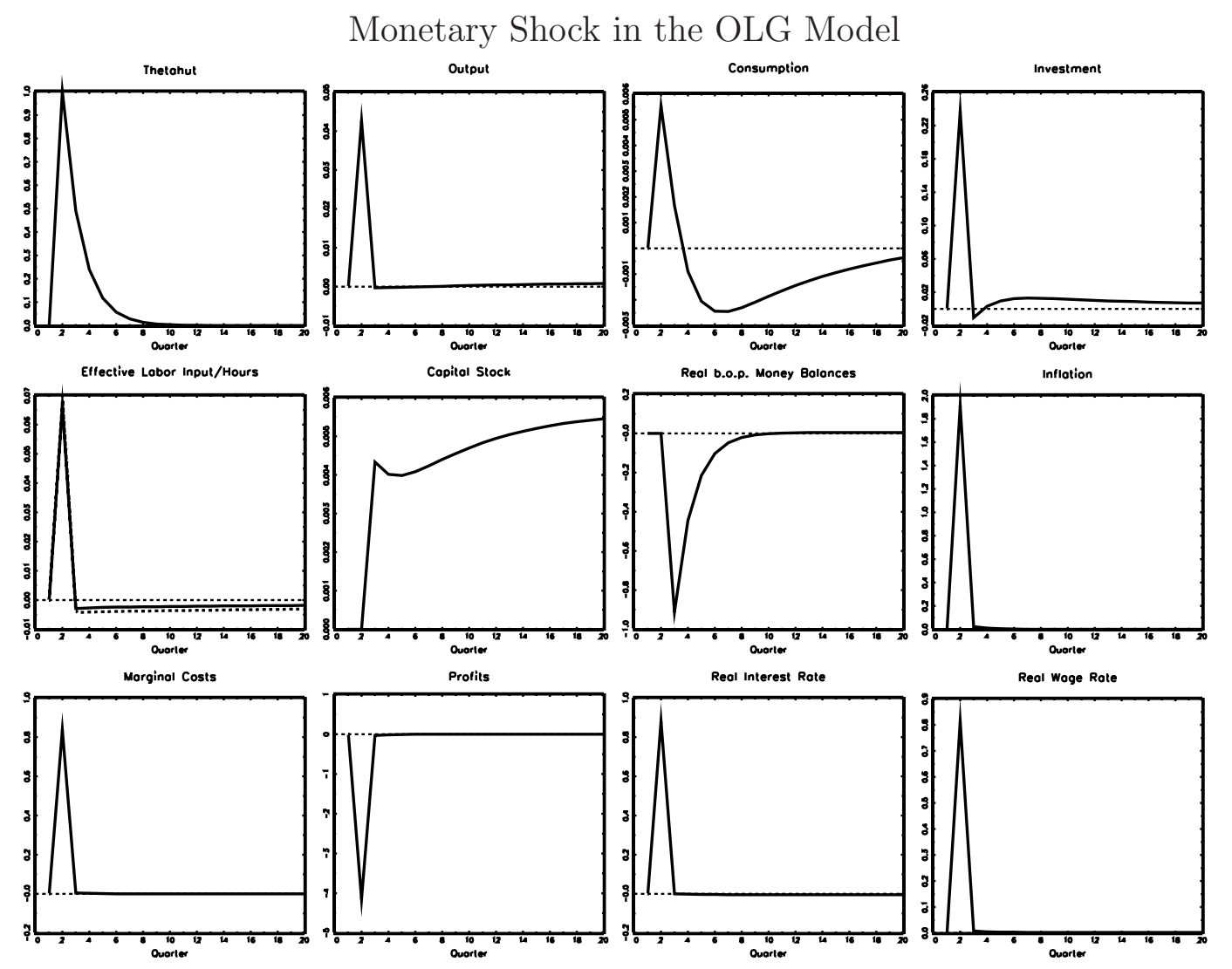

The percentage changes of output, hours and investment are small and only amount to $0.04 \%, 0.07 \%$ and $0.24 \%$, respectively. Inflation, the real interest rate, and wages all increase. Notice that, in this sticky price model, we are unable to model the liquidity effect that nominal interest rates decrease following an expansionary monetary policy. In addition, profits decline. This is one of the major shortcoming of the sticky-price model that has been documented in the literature. ${ }^{16}$

The impulses responses of the Gini coefficients of capital, money, wealth, and income are displayed in Figure 5. As in the case of an expansionary technology shock, the distribution of market income becomes more unequal. The labor supply of the more productive households is more elastic with respect to the real wage. Therefore, the wage income of those households increases by more than the wage income of the less productive households. In addition, the latter gain less from the increased rental rate

\footnotetext{
${ }^{16}$ See, among others, Christiano, Eichenbaum, and Evans (1997).
} 
Figure 6

Monetary shock in the OLG model and distribution

Gini capital

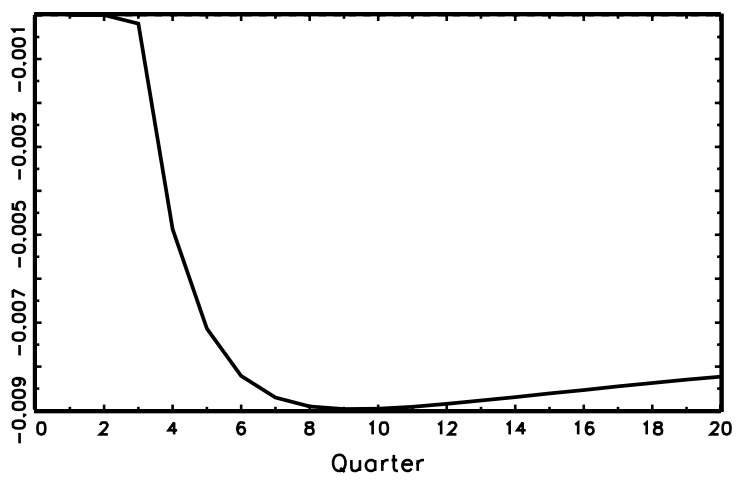

Gini wealth

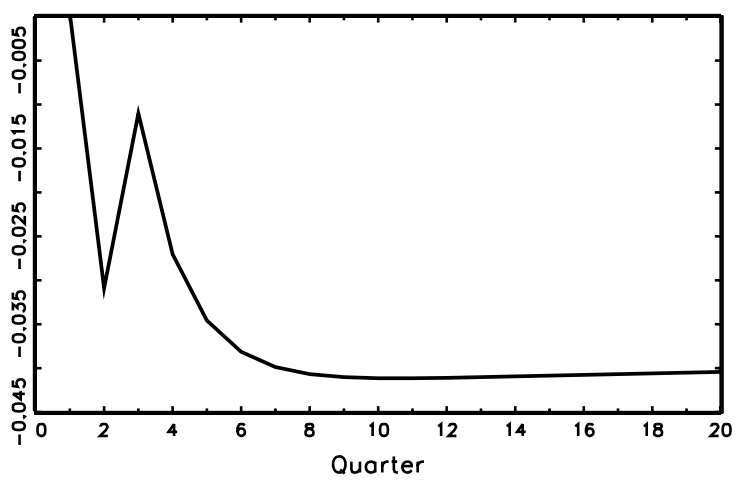

Gini money

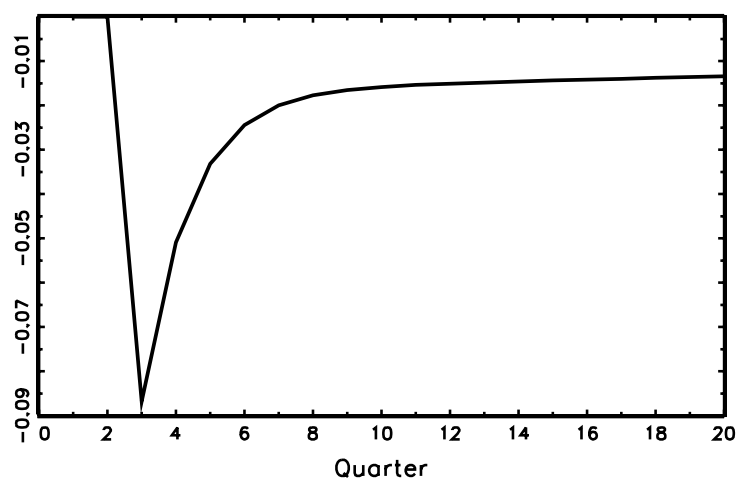

Gini market/disposable income

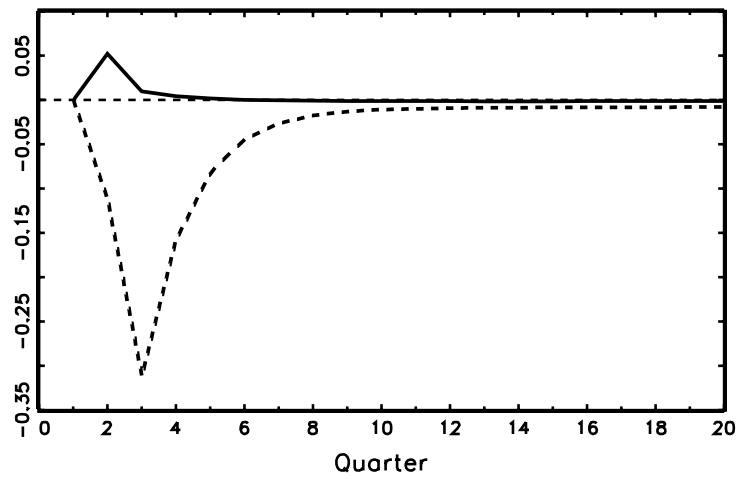

of capital services. Again, the transfer and tax system more than compensates these effects. Since the real value of pensions sharply declines in first period of the shock transfers sore by more than 30 percent. In the next four periods transfers are still well above 1 percent as compared to their non-stochastic long run level. The additional wage and capital income of the richer agents is taxed at a higher rate. As a consequence of both effects the distribution of disposable income becomes more equal.

The impulse response functions of the aggregate variables in the Ramsey model with Calvo price staggering are graphed in Figure 7 (the dotted lines). Again the ordering of the variables is identical to the one in Figure 5. Notice that the qualitative behavior of the variables in response to a monetary expansion is the same in the two economies for all variables with a minor exception. In the OLG model, there is a little more consumption smoothing than in the representative-agent economy so that the capital 
Figure 7

Monetary Shock in the Representative Agent Economy
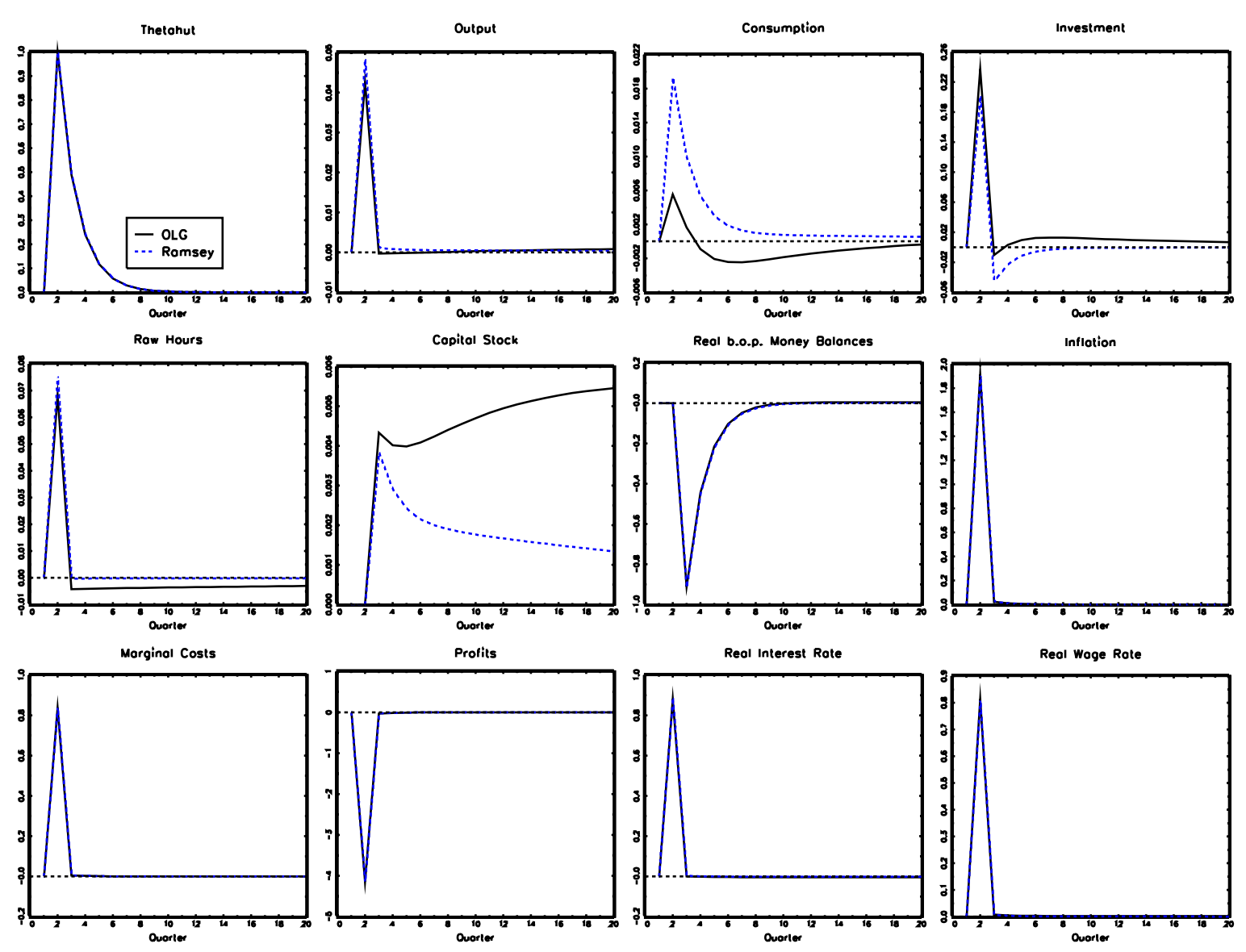

stock remains above its non-stochastic level for many quarters.

We conclude this section by a comparison of the time series properties of the OLG and the Ramsey model. For this purpose we compute 100 simulations of 150 periods length each $^{17}$ and filter each simulated time series using the HP-filter with weight 1,600. The time series moments reported in Table 2 are averages over the 100 simulations. The technology shock and the growth shock are generated by the processes (14) and (18), respectively. We use the same sequence of shocks for the OLG and the Ramsey model. The first column in Table 2 presents the aggregate variable. In the second and fifth column, the standard deviation of the respective variables are displayed. Columns 3 and 6 display the correlation with output, while columns 4 and 7 present the autocorrelation of the variables in the two models, respectively.

\footnotetext{
${ }^{17}$ See, e.g., Cooley and Hansen (1995), p. 189.
} 
Table 2

Business Cycle Statistics

\begin{tabular}{lcccccc}
\hline \hline & \multicolumn{3}{c}{ OLG model } & \multicolumn{3}{c}{ Ramsey model } \\
Variable & $s_{x}$ & $r_{x y}$ & $r_{x}$ & $s_{x}$ & $r_{x y}$ & $r_{x}$ \\
\hline Output & 0.89 & 1.00 & 0.69 & 0.89 & 1.00 & 0.69 \\
Investment & 3.79 & 1.00 & 0.69 & 3.73 & 1.00 & 0.69 \\
Consumption & 0.35 & 0.98 & 0.72 & 0.37 & 0.98 & 0.72 \\
Effective Labor & 0.07 & 0.20 & 0.33 & & & \\
Hours & 0.07 & -0.03 & 0.19 & 0.08 & 0.33 & 0.17 \\
Real Wage & 1.09 & 0.78 & 0.43 & 1.08 & 0.79 & 0.43 \\
Inflation & 1.66 & -0.05 & -0.09 & 1.66 & -0.05 & -0.08 \\
Gini Wealth & 0.07 & -0.11 & 0.87 & & & \\
Gini Net Income & 0.31 & -0.33 & 0.52 & & & \\
\hline
\end{tabular}

Notes: $s_{x}:=$ standard deviation of HP-filtered simulated series of variable $x$, $r_{x y}:=$ cross correlation of variable $x$ with output, $r_{x}:=$ first order autocorrelation of variable $x$.

The second moments in Table 2 corroborate the impression conveyed by the impulse response functions. The two models are very similar. There are negligible differences in the standard deviations of investment, consumption, hours, and the real wage. Except for hours and the inflation factor the first-order autocorrelations are the same in both models. Merely the cross correlation of hours with output differs between the two models. Hours are slightly procyclical in the Ramsey model $\left(r_{x y}=0.33\right)$ and uncorrelated $\left(r_{x y}=-0.03\right)$ in the OLG model. Notice further that the wealth distribution is almost unrelated to output $\left(r_{x y}=-0.11\right)$ and the inequality of the income distribution is weakly anti-cyclical $\left(r_{x y}=-0.33\right)$. The behavior of the income distribution is in good accordance with empirical evidence collected by Castañeda et al. (1998). They find that the lower income quintiles of the income distribution in the US are procyclical, while the fourth quintile and and next $15 \%$ of the income distribution are negatively correlated with income. Consequently, the Gini coefficient of income in the 
US is anti-cyclical as in our OLG model. ${ }^{18}$

\section{Conclusion}

We find that the business cycle dynamics of the heterogeneous-agent OLG economy are very similar to those found in the corresponding representative-agent economy. Our result is in very good accordance with those of Ríos-Rull (1996). Different from his study, however, we also consider a non-Walrasian economy with i) sticky prices, ii) within-generation heterogeneity, iii) quarterly periods, and iv) a monetary shock. The aggregate variables in our heterogenous-agent OLG model behave almost identical to those in the corresponding representative-agent model with one exception. In particular, we find that aggregate hours decrease in response to a positive technology shock in the OLG model whereas hours increase in the Ramsey model. Thus, heterogeneous labor may account for the observed negative response of hours to a technology shock found in a number of empirical papers.

Our study also increases the understanding of the distributional effects of monetary policy. So far, only the long-run distribution effects of monetary policy have been analyzed in computable general equilibrium models, as e.g. in Erosa and Ventura (2002) or Heer and Süssmuth (2006). The short-run effect of unexpected inflation on the distribution of wealth, to the best of our knowledge, have not received any attention yet. In this paper, we presented a model framework for the analysis of the distribution effects of unanticipated inflation. An expansionary monetary shock is found to increase the inequality of the distribution of factor income, even though only to a small extent. Due to the tax and transfer system, however, the distribution of disposable income becomes more equal and gives raise to a more equal distribution of wealth.

Our framework can only be regarded as a first step to a fully-fledged analysis of the short-run distribution effects of monetary policy. Nevertheless, our model can serve as a benchmark case for future work that may include a more sophisticated modelling of the idiosyncratic earnings process and may even allow for a third asset besides money and capital, namely housing. In particular, we suggested a framework that replicates the following important channels of monetary policy on the distribution of income

\footnotetext{
${ }^{18}$ Different from us, however, Castañeda et al. (1998) consider annual periods rather than quarterly periods.
} 
and wealth: 1) the "bracket creep" effect, 2) inflation-dependent pensions, and 3) the response of prices, and hence the change in the mark-ups, interest rates, wages and, ultimately, the factor incomes of the individuals. 


\section{Appendix}

\subsection{Non-stochastic steady state of the OLG model}

In the stationary state state of the OLG model (constant money growth $\bar{\theta}$ and $z_{t} \equiv 1$ ), the following equilibrium conditions hold:

1. $\pi=\bar{\theta}$

2. $\bar{x}=\frac{\epsilon}{\epsilon-1}$.

3. $r=\frac{1}{x} \alpha K^{\alpha-1} N^{1-\alpha}-\delta$

4. $w=\frac{1}{x}(1-\alpha) K^{\alpha} N^{-\alpha}$.

5. $\Omega=\left(1-\frac{1}{x}\right) K^{\alpha} N^{1-\alpha}$.

6. seign $=\frac{\text { Seignt }_{t}}{P_{t}}=(\bar{\theta}-1) \sum_{j=1}^{n e} \sum_{s=2}^{T+T^{R}} \frac{\mu(j)}{T+T^{R}} \frac{M}{P}+\sum_{j=1}^{n e} \frac{\mu(j)}{T+T^{R}} \frac{M^{1 j}}{P}$.

\subsection{The log-linear OLG model}

In our model there are $n e\left[2\left(T+T^{R}-1\right)\right]$ variables with given initial conditions: the capital and cash holdings of generations $s=2,3, \ldots, T+T^{R}$. ${ }^{19}$ We summarize these in the vectors $\mathbf{k}_{t}^{j}:=\left[k_{t}^{2, j}, k_{t}^{3, j}, \ldots, k_{t}^{T+T^{R}, j}\right]^{\prime}$, and $\mathbf{m}_{t}^{j}:=\left[m_{t}^{2, j}, m_{t}^{3, j}, \ldots, m_{t}^{T+T^{R}, j}\right]^{\prime}$, $m_{t}^{s, j}:=M_{t}^{s, j} / P_{t-1}, j=1,2, \ldots, n e$. In addition, there are $n e\left(T+T^{R}-1\right)+2$ variables that are also predetermined at time $t$. These variables are the $n e\left(T+T^{R}-1\right)$ Lagrange multipliers $\boldsymbol{\lambda}_{t}^{j}:=\left[\lambda_{t}^{1, j}, \lambda_{t}^{2, j}, \ldots, \lambda_{t}^{T+T^{R}-1, j}\right]^{\prime}, j=1,2, \ldots, n e$, the inflation factor $\pi_{t}$ and marginal costs $g_{t}$. The initial values of these variables must be chosen so that the transversality conditions hold. For given vectors $\mathbf{x}_{t}:=\left[\mathbf{k}_{t}^{2}, \mathbf{m}_{t}^{2}, \mathbf{k}_{t}^{3}, \mathbf{m}_{t}^{3}, \ldots, \mathbf{k}_{t}^{n e}, \mathbf{m}_{t}^{n e}\right]^{\prime}$ $\boldsymbol{\lambda}_{t}:=\left[\boldsymbol{\lambda}_{t}^{1}, \boldsymbol{\lambda}_{t}^{2}, \ldots, \boldsymbol{\lambda}_{t}^{n e}, \pi_{t}, g_{t}\right]^{\prime}$ the model's equations determine the vector $\mathbf{u}_{t}$. The elements of this vector are

- consumption $\mathbf{c}_{t}:=\left[c_{t}^{1,1}, \ldots c_{t}^{T+T^{R}, 1}, \ldots, c_{t}^{1, n e}, \ldots, c_{t}^{T+T^{R}, n e}\right]^{\prime}$,

- working hours $\mathbf{n}_{t}:=\left[n_{t}^{1,1}, \ldots n_{t}^{T, 1}, \ldots, n_{t}^{1, n e}, \ldots, n_{t}^{T, n e}\right]^{\prime}$,

\footnotetext{
${ }^{19}$ Since we assume that the cash transfer to the newborn, $M_{t}^{1 j} / P_{t-1}$ remain unchanged, we can ignore these additional ne state variables.
} 
- market income $\mathbf{y}_{t}:=\left[y_{t}^{1,1}, \ldots y_{t}^{T+T^{R}, 1}, \ldots, y_{t}^{1, n e}, \ldots, y_{t}^{T+T^{R}, n e}\right]^{\prime}$,

- the rental rate of capital $r_{t}$, the real wage $w_{t}$, the aggregate capital stock $K_{t}$, effective aggregate labor input $N_{t}$, the beginning-of-period stock of real money balances $m_{t}$, aggregate transfers $T r_{t}$, and aggregate profits $\Omega_{t}$. Thus, $\mathbf{u}_{t}$ is a vector of $n e\left[2\left(T+T^{R}\right)+T\right]+7$ elements.

We seek a representation of our model in the form

$$
\begin{gathered}
C_{u} \hat{\mathbf{u}}_{t}=C_{x \lambda}\left[\begin{array}{c}
\hat{\mathbf{x}}_{t} \\
\hat{\boldsymbol{\lambda}}_{t}
\end{array}\right]+C_{z}\left[\begin{array}{c}
\hat{z}_{t} \\
\hat{\theta}_{t}
\end{array}\right], \\
D_{x \lambda} E_{t}\left[\begin{array}{c}
\hat{\mathbf{x}}_{t+1} \\
\hat{\boldsymbol{\lambda}}_{t+1}
\end{array}\right]+F_{x \lambda}\left[\begin{array}{c}
\hat{\mathbf{x}}_{t} \\
\hat{\boldsymbol{\lambda}}_{t}
\end{array}\right]=D_{u} E_{t} \hat{\mathbf{u}}_{t+1}+F_{u} \hat{\mathbf{u}}_{t}+D_{z} E_{t}\left[\begin{array}{c}
\hat{z}_{t+1} \\
\hat{\theta}_{t+1}
\end{array}\right]+F_{z}\left[\begin{array}{c}
\hat{z}_{t} \\
\hat{\theta}_{t}
\end{array}\right],
\end{gathered}
$$

where the hat denotes percentage deviations from the non-stochastic steady state value of a variable.

We first derive the set of equations (26a). The log-linearized Euler equations (6) $\operatorname{are}^{20}$

$$
\begin{aligned}
\hat{\lambda}_{t}^{s, j} & =(\gamma(1-\sigma)-1) \hat{c}_{t}^{s, j}+(1-\gamma)(1-\sigma)\left[\hat{m}_{t}^{s, j}-\hat{\pi}_{t}\right], \\
s & =1, \ldots, T+T^{R}, \quad j=1, \ldots, n e ., \\
\hat{m}_{t}^{1, j} & =0 \forall j=1, \ldots, n e .
\end{aligned}
$$

The log-linearized Euler equations (9) are:

$$
\begin{aligned}
\eta \frac{n^{s j}}{1-n^{s, j}} \hat{n}_{t}^{s, j}+\frac{\tau^{\prime \prime}}{1-\tau^{\prime}} y^{s, j} \hat{y}_{t}^{s, j}-\hat{w}_{t} & =\hat{\lambda}_{t}^{s, j}-\frac{\tau^{\prime}+\tau^{\prime \prime} y^{s, j}}{1-\tau^{\prime}} \hat{\pi}_{t}, \\
s & =1,2, \ldots, T, j=1,2, \ldots, n e,
\end{aligned}
$$

where $\tau^{\prime}$ and $\tau^{\prime \prime}$ denote the first and second derivative of the tax function evaluated at $y^{s, j}$, respectively. The $n e\left(T+T^{R}\right)$ definitions of market income yield:

$$
\begin{aligned}
0 & =y^{1, j} \hat{y}_{t}^{1, j}-w e(1, j) n^{1, j} \hat{n}_{t}^{1, j}-w e(1, j) n^{1, j} \hat{w}_{t}, \\
j & =1, \ldots, n e \\
r k^{s, j} \hat{k}_{t}^{s, j} & =y^{s, j} \hat{y}_{t}^{s, j}-w e(s, j) n^{s, j} \hat{n}_{t}^{s, j}-w e(s, j) n^{s, j} \hat{w}_{t}-r k^{s, j} \hat{r}_{t}, \\
s & =2, \ldots, T, j=1, \ldots, n e, \\
r k^{s, j} \hat{k}_{t}^{s, j} & =y^{s, j} \hat{y}_{t}^{s, j}-r k^{s, j} \hat{r}_{t}, \\
s & =T+1, \ldots, T+T^{R}, \\
j & =1, \ldots, n e .
\end{aligned}
$$

\footnotetext{
${ }^{20}$ We will use the ne equations for generation $T+T^{R}$ later to eliminate $\hat{\lambda}_{t}^{T+T^{R}, j}$, which is a control rather than a costate variable.
} 
The log-linearized budget equations for generation $s=T+T^{R}$ are:

$$
\begin{aligned}
& c^{T+T^{R}, j} \hat{c}_{t}^{T+T^{R}, j}-\left(1-\tau^{\prime}\right) y^{T+T^{R}, j} \hat{y}^{T+T^{R}, j}-\operatorname{trtr_{t}}-\Omega \hat{\Omega}_{t} \\
& =(1-\delta) k^{T+T^{R}, j} \hat{k}_{t}^{T+T^{R}, j}+m^{T+T^{R}, j} \hat{m}^{T+T^{R}, j}-\left(\tau^{\prime} y^{T+T^{R}, j}+\text { pens }+m^{T+T^{R}, j}\right) \hat{\pi}_{t}, \\
& j=1, \ldots, \text { ne. }
\end{aligned}
$$

From the factor market equilibrium conditions (15) and (16) we obtain:

$$
\begin{gathered}
\hat{w}_{t}+\alpha \hat{N}_{t}=\alpha \hat{K}_{t}+\hat{g}_{t}+\hat{z}_{t}, \\
\hat{r}_{t}+(\alpha-1) \hat{N}_{t}=(\alpha-1) \hat{K}_{t}+\hat{g}_{t}+\hat{z}_{t} .
\end{gathered}
$$

From aggregate profits $\Omega_{t}=\left(1-g_{t}\right) z_{t} N_{t}^{1-\alpha} K^{\alpha}$, we derive

$$
\hat{\Omega}_{t}-(1-\alpha) \hat{N}_{t}=\alpha \hat{K}_{t}+(1-\epsilon) \hat{g}_{t}+\hat{z}_{t} .
$$

The aggregate consistency conditions (23c), (23b), and (23d), imply

$$
\begin{aligned}
K \hat{K} & =\sum_{j=1}^{n e} \sum_{s=2}^{T+T^{R}} \frac{\mu(j)}{T+T^{R}} k^{s, j} \hat{k}_{t}^{s, j}, \\
N \hat{N} & =\sum_{j=1}^{n e} \sum_{s=1}^{T} \frac{\mu(j)}{T+T^{R}} n^{s, j} \hat{n}_{t}^{s, j}, \\
m \hat{m}_{t} & =\sum_{j=1}^{n e} \sum_{s=2}^{T+T^{R}} \frac{\mu(j)}{T+T^{R}} m^{s, j} \hat{m}_{t}^{s, j} .
\end{aligned}
$$

Finally, the log-linearized budget constraint of the government (21) is given by:

$$
\begin{aligned}
& \sum_{j=1}^{n e} \sum_{s=1}^{T+T^{R}} \frac{\mu(j)}{T+T^{R}} \tau^{\prime} y^{s, j} \hat{y}_{t}^{s, j}-t r \hat{r}_{t}=(1-\theta) m \hat{m}_{t} \\
& +\left(-\sum_{j=1}^{n e} \sum_{s=1}^{T+T^{R}} \frac{\mu(j)}{T+T^{R}} \tau^{\prime} y^{s, j}+(\theta-1) \tilde{m}+(m-\tilde{m})-\frac{T^{R}}{T+T^{R}} \text { pens }\right) \hat{\pi}_{t}-\theta \tilde{m} \hat{\theta}_{t},
\end{aligned}
$$

where $\tilde{m}=m-\sum_{j=1}^{n e}\left(\mu(j) /\left(T+T^{R}\right)\right) m^{1, j}$.

Next we derive the set of equations (26b). We begin with the log-linearized budget equations of generation $s=1$. From (5) we derive:

$$
\begin{aligned}
& k^{2, j} \hat{k}_{t+1}^{2, j}+\theta m^{2, j} \hat{m}_{t+1}^{2, j}+\left(\tau^{\prime} y^{1, j}+m^{1, j}\right) \hat{\pi}_{t}=\left(1-\tau^{\prime}\right) y^{1, j} \hat{y}_{t}^{1, j}+\operatorname{trtr_{t}}+\Omega \hat{\Omega}_{t}-c^{1, j} \hat{c}_{t}^{1, j}, \\
& j=1, \ldots, n e .
\end{aligned}
$$


For generations $s=2, \ldots, T$ the log-linearized budget equations (5) are:

$$
\begin{aligned}
& k^{s+1, j} \hat{k}_{t+1}^{s+1, j}+\theta m^{s+1, j} \hat{m}_{t+1}^{s+1, j}-(1-\delta) k^{s,} \hat{k}_{t}^{s, j}-m^{s, j} \hat{m}_{t}^{s, j}+\left(\tau^{\prime} y^{s, j}+m^{s, j}\right) \hat{\pi}_{t} \\
& =\left(1-\tau^{\prime}\right) y^{s, j} \hat{y}_{t}^{s, j}+t r t \hat{r}_{t}+\Omega \hat{\Omega}_{t}-c^{s, j} \hat{c}_{t}^{s, j}, \\
& j=1, \ldots, n e, s=2, \ldots, T .
\end{aligned}
$$

For generations $s=T+1, \ldots, T+T^{R}-1$ they are:

$$
\begin{aligned}
& k^{s+1, j} \hat{k}_{t+1}^{s+1, j}+\pi m^{s+1, j} \hat{m}_{t+1}^{s+1, j}-(1-\delta) k^{s, j} \hat{k}_{t}^{s, j}-m^{s, j} \hat{m}_{t}^{s, j}+\left(\tau^{\prime} y^{s, j}+m^{s, j}+p e n s\right) \hat{\pi}_{t} \\
& =\left(1-\tau^{\prime}\right) y^{s, j} \hat{y}_{t}^{s, j}+\operatorname{trt} \hat{r}_{t}+\Omega \hat{\Omega}_{t}-c^{s, j} \hat{c}_{t}^{s, j}, \\
& j=1, \ldots, n e, s=2, \ldots, T .
\end{aligned}
$$

The Euler equations (7) and (8) yield:

$$
\begin{aligned}
& \hat{\lambda}_{t+1}^{s+1, j}-\hat{\lambda}_{t}^{s, j}-\beta r \frac{\lambda^{s+1, j}}{\lambda^{s, j}}\left(\tau^{\prime}+\tau^{\prime \prime} y^{s+1, j}\right) \hat{\pi}_{t+1} \\
& =\beta r \frac{\lambda^{s+1, j}}{\lambda^{s, j}} \tau^{\prime \prime} y^{s+1, j} \hat{y}_{t}^{s+1, j}-\beta r \frac{\lambda^{s+1, j}}{\lambda^{s, j}}\left(1-\tau^{\prime}\right) \hat{r}_{t+1}, \\
& \frac{\beta}{\pi} \frac{\lambda^{s+1, j}}{\lambda^{s, j}} \hat{\lambda}_{t+1}^{s+1, j}-\hat{\lambda}_{t}^{s, j}-\left[1+\left(1-\frac{\beta}{\pi} \frac{\lambda^{s+1, j}}{\lambda^{s, j}}\right)[(1-\gamma)(1-\sigma)-1]\right] \hat{\pi}_{t+1} \\
& +[(1-\gamma)(1-\sigma)-1]\left(1-\frac{\beta}{\pi} \frac{\lambda^{s+1, j}}{\lambda^{s, j}}\right) \hat{m}_{t+1}^{s+1, j} \\
& =-\gamma(1-\sigma)\left(1-\frac{\beta}{\pi} \frac{\lambda^{s+1, j}}{\lambda^{s, j}}\right) \hat{c}_{t+1}^{s+1, j}, \\
& j=1, \ldots, n e, s=1, \ldots, T+T^{R}-1 .
\end{aligned}
$$

Note that in the equations for $s=T+T^{R}-1$ we must replace $\hat{\lambda}_{t+1}^{T+T^{R}, j}$ by the right hand side of (27) for $t+1$ and $s=T+T^{R}$. The remaining two equations are given by the New Keynesian Phillips curve equation (17),

$$
\beta \hat{\pi}_{t+1}-\hat{\pi}_{t}+\frac{(1-\phi)(1-\beta \phi)}{\phi} \hat{g}_{t}=0,
$$

and the log-linearized definition of the aggregate beginning-of-period real stock of money $m_{t}:=M_{t} / P_{t-1}$. Together with equation (18) this definition implies:

$$
\hat{m}_{t+1}-\hat{m}_{t}+\hat{\pi}_{t}=\hat{\theta}_{t}
$$


The $n e\left[2\left(T+T^{R}\right]+T\right]+7$ equations (27) through (34) define $\hat{\mathbf{u}}_{t}$ for given $\hat{\mathbf{x}}_{t}$ and $\hat{\boldsymbol{\lambda}}_{t}$. The dynamics of the system is then determined from the $n e\left[3\left(T+T^{R}-1\right)\right]+2$ equations (35) through (41).

The log-linear system (26) is determined if $n e\left[2\left(T+T^{R}-1\right)\right]$ of its Eigenvalues are within the unit circle and if $n e\left(T+T^{R}-1\right)+2$ Eigenvalues are outside the unit circle. This condition holds in our calibration.

\subsection{Non-stochastic steady state of the Ramsey model}

The stationary solution of the representative agent model is characterized by the following set of equations. Since real money balances are constant, the inflation factor $\pi$ equals the money growth factor $\theta$ :

$$
\pi=\theta
$$

Calvo price staggering implies

$$
g=\frac{\epsilon-1}{\epsilon} .
$$

The stationary version of the Euler equation for capital,

$$
\frac{1-\beta(1-\delta)}{\alpha \beta g}=n^{1-\alpha} k^{\alpha-1} \tau^{\prime}\left[g n^{1-\alpha} k^{\alpha}\right]
$$

can be solved for $k$ given our predetermined value of $n=0.33$. Given the solution for $k$ we can determine $y$. The stationary version of the economy's resource constraint,

$$
y=c+\delta k
$$

allows us, then, to compute $c$. Finally, the Euler equation (25c) implies the stationary solution for the ratio between consumption and real money balances:

$$
\frac{C}{M / P}=\frac{\gamma}{1-\gamma}\left[\frac{\mu}{\beta}-1\right] .
$$

We use this equation and (42c) to determine the value of $\gamma$. This is all we need to compute the policy function of the log-linearized model. 


\subsection{The log-linear Ramsey model}

The log-linear version of (25a) is given by

$$
[\gamma(1-\sigma)-1] \hat{c}_{t}=-(1-\gamma)(1-\sigma) \hat{m}_{t}+\hat{\lambda}_{t}+(1-\gamma)(1-\sigma) \hat{\pi}_{t}
$$

Log-linearizing (25e) delivers:

$$
\eta \frac{n}{1-n} \hat{n}_{t}-\hat{w}_{t}+\frac{\tau^{\prime \prime} g y}{1-\tau^{\prime}} \hat{y}_{t}=\hat{\lambda}_{t}-\frac{\tau^{\prime}+\tau^{\prime \prime} g y}{1-\tau^{\prime}} \hat{\pi}_{t}-\frac{\tau^{\prime \prime} g y}{1-\tau^{\prime}} \hat{g}_{t}
$$

where $\tau^{\prime}\left(\tau^{\prime \prime}\right)$ is the marginal tax rate (the second derivative of the tax function) computed at the steady state solution of $g y=w n+r k$. The cost-minimizing conditions (16) and (15) provide two additional equations:

$$
\begin{aligned}
\alpha \hat{n}_{t}+\hat{w}_{t} & =\alpha \hat{k}_{t}-\hat{x}_{t}+\hat{z}_{t} \\
(\alpha-1) \hat{n}_{t}+\hat{r}_{t} & =(\alpha-1) \hat{k}_{t}-\hat{x}_{t}+\hat{z}_{t} .
\end{aligned}
$$

The log-linear version of the aggregate production function is given by:

$$
(\alpha-1) \hat{n}_{t}+\hat{y}_{t}=\alpha \hat{k}_{t}+\hat{z}_{t}
$$

The definition of gross investment $i_{t}=y_{t}-c_{t}$ implies

$$
[(y / i)-1] \hat{c}_{t}-(y / i) \hat{y}_{t}+\hat{i}_{t}=0
$$

Finally, the profit equation $\Omega_{t}=y_{t}\left(1-g_{t}\right)$ ) provides the following log-linear equation:

$$
-\hat{y}_{t}+\hat{\Omega}_{t}=(1-\epsilon) \hat{g}_{t}
$$

The five equations that determine the dynamics of the log-linear model are derived from the economy's resource constraint $k_{t+1}=(1-\delta) k_{t}+y_{t}-c_{t}$, the Euler equations for capital and money balances, (25b) and (25c), the definition of beginning-of-period 
money balances (24), and from the Calvo price staggering model:

$$
\begin{aligned}
\hat{k}_{t+1}+(\delta-1) \hat{k}_{t} & =(y / k) \hat{y}_{t}-(c / k) \hat{c}_{t} \\
E_{t} \hat{\lambda}_{t+1}-\hat{\lambda}_{t}-\beta r \frac{\tau^{\prime}+\tau^{\prime \prime} g y}{1-\tau^{\prime}} E_{t} \hat{\pi}_{t+1} & \\
-\beta r \tau^{\prime \prime} g y E_{t} \hat{g}_{t+1} & \\
& =\beta r \tau^{\prime \prime} g y E_{t} \hat{y}_{t+1}-\beta r\left(1-\tau^{\prime}\right) E_{t} \hat{r}_{t+1},
\end{aligned}
$$

$$
\begin{aligned}
(\beta / \pi) E_{t} \hat{\lambda}_{t+1}-\hat{\lambda}_{t}-\Delta_{1} E_{t} \hat{\pi}_{t+1}+\Delta_{2} E_{t} \hat{m}_{t+1} & =-\Delta_{3} E_{t} \hat{c}_{t+1}, \\
E_{t} \hat{m}_{t+1}-\hat{m}_{t}+\hat{\pi}_{t} & =\hat{\theta}_{t}, \\
\beta E_{t} \hat{\pi}_{t+1}-\hat{\pi}_{t}+\frac{(1-\phi)(1-\beta \phi)}{\phi} \hat{g}_{t} & =0 \\
1+(1-(\beta / \pi))[(1-\gamma)(1-\sigma)-1] & =: \Delta_{1}, \\
\Delta_{1}-1 & =: \Delta_{2}, \\
(1-(\beta / \pi)) \gamma(1-\sigma) & =: \Delta_{3} .
\end{aligned}
$$




\section{References}

Altonij, J.G., 1986, Intertemporal Substitution in Labor Supply: Evidence from Micro Data, Journal of Political Economics, vol. 94, S17-S215.

Basu, S., and J. Fernald, 1997, Returns to Scale in US Production: Estimates and Implications, Journal of Political Economy, vol. 105, 249-283.

Bernanke, B.S., M. Gertler and S. Gilchrist, 1999, The Financial Accelerator in a Quantitative Business Cycle Framework, in: J.B. Taylor and M. Woodford (eds.), Handbook of Macroeconomics, vol. 1C, Ch. 19, 1232-1303.

Blanchard, O. J. and Ch. M. Kahn, 1980, The Solution of Linear Difference Models Under Rational Expectations, Econometrica, vol. 48, 1305-1311.

Calvo, G., 1983, Staggered Prices in a Utility-Maximizing Framework, Journal of Monetary Economics, vol. 12, 383-98.

Castañeda, A., J. Díaz-Giminénez, J.-V. Ríos-Rull, 1998, Exploring the income distribution business cycle dynamics, Journal of Monetary Economics, vol. 42, 93-130.

Castañeda, A., J. Díaz-Giminénez, J.-V. Ríos-Rull, 2004, Accounting for the US Earnings and Wealth Inequality, Journal of Political Economy, forthcoming.

Christiano, L.J., M. Eichenbaum, and C. Evans, 1997, Sticky price and limited participation models of money: A comparison, European Economic Review, vol. 41, 1201-49.

Christiano, L.J., M. Eichenbaum, and R. Vigfusson, 2003, What Happens After a Technology Shock?, National Bureau of Economic Research (NBER) Working Paper No. W9819.

Cooley, T.F., and G.D. Hansen, 1995, Money and the Business Cycle, in: Cooley, T.F., ed., Frontiers of Business Cycle Research, Princeton University Press.

Díaz-Giménez, J., V. Quadrini, and J.V. Ríos-Rull, 1997, Dimensions of Inequality: Facts on the U.S. Distributions of Earnings, Income, and Wealth, Federal Reserve Bank of Minneapolis Quarterly Review 21, 3-21.

Domeij, D., and M. Floden, 2006, The labor supply elasticity and borrowing constraints: Why estimates are biased, Review of Economic Dynamics, forthcoming.

Easterly, W., and S. Fischer, 2001, Inflation and the Poor, Journal of Money, Credit, and Banking, vol. 33, 160-78.

Erosa, A., and G. Ventura, 2002, On inflation as a regressive consumption tax, Journal of Monetary Economics, vol. 49, 761-95. 
Francis, N., and V.A. Ramey, 2002, Is the Technology-Driven Real Business Cycle Hypothesis Dead? Shocks and Aggregate Fluctuations Revisited, National Bureau of Economic Research (NBER) Working Paper 8726.

Galí, J., 1999, Technology, Employment, and the Business Cycle: Do Technology Schocks Explain Aggregate Fluctuations?, American Economic Review, vol. 89, 249-271.

Galli, R., and R. van der Hoeven, 2001, Is Inflation Bad for Income Inequality: The Importance of the Initial Rate of Inflation, International Labor Organization Employment Paper 2001/29.

Gouveia, M., and R.O. Strauss, 1994, Effective Federal Individual Income Tax Functions: An Exploratory Empirical Analysis, National Tax Journal, vol. 47(2), 31739.

Greenwood, D., 1983, An Estimation of US Family Wealth and Its Distribution from Microdata, 1973, Review of Income and Wealth, vol. 24, 23-44.

Hansen, G., 1993, The cyclical and secular behavior of the labor input: comparing efficiency units and hours worked, Journal of Applied Econometrics 8, 71-80.

Heer, B., and A. Maußner, 2005, Dynamic General Equilibrium Modelling: Computational Methods and Applications, Springer: Berlin.

Heer, B., und B. Süssmuth, 2006, Effects of Inflation and Wealth Distribution: Do stock market participation fees and capital income taxation matter?, Journal of Economic Dynamics and Control, forthcoming.

Henle, P., and P. Ryscavage, 1980, The distribution of earned income among men and women 1958-77, Monthly Labor Review, April, 3-10.

Huggett, M., 1996, Wealth distribution in Life-Cycle Economies, Journal of Monetary Economics, vol. 17, 953-69.

Kessler, D., and E.N. Wolff, 1992, A Comparative Analysis of Household Wealth Patterns in France and the United States, Review of Income and Wealth, vol. 37, $249-66$.

Killingsworth, M.R., 1983, Labor Supply, Cambridge University Press, Cambridge, MA.

King, R. G., Ch. I. Plosser, and S. Rebelo, 1988, Production, Growth and Business Cycles I, The Basic Neoclassical Model, Journal of Monetary Economics, vol. 21, 195-232.

King, R.G., and M.W. Watson, 2002, System Reduction and Solution Algorithms for Singular Linear Difference Systems under Rational Expectations, Computational Economics, vol. 20, 57-86. 
Krussell, P., and A.A. Smith, 1998, Income and Wealth Heterogeneity in the Macroeconomy, Journal of Political Economy, vol. 106, 867-96.

MaCurdy, T.E., 1981, An Empirical Model of Labor Supply in a Life-Cycle Setting, Journal of Political Economy, vol. 89, 1059-85.

Prescott, E., 1986, Theory ahead of Business Cycle Measurement, Federal Reserve Bank of Minneapolis Quarterly Review 10, 9-22.

Quadrini, V., 2000, Entrepreneurship, Saving and Social Mobility, Review of Economic Dynamics, vol. 3, 1-40.

Ríos-Rull, J.V., 1996, Life-Cycle Economies and Aggregate Fluctuations, Review of Economic Studies, vil. 63, 465-89.

Romer, C.D., and D.H. Romer, 1998, Monetary Policy and the Well-Being of the Poor, NBER Working Paper Series, Working Paper 6793.

Wolff, E., 1987, Estimate of household wealth inequality in the US, 1962-1983, Review of Income and Wealth, vol. 33, 231-57. 